\title{
ALGUMAS NOTAS SOBRE A HISTORIA DA VIAÇÃO URBANA NO VELHO SÃO PAULO (*).
}

\section{GERALD MICHAEL GREENFIELD}

Durante a maior parte de sua história, a cidade de São Paulo gozou de uma posição de primazia que derivou, em grande parte, de sua localização geográfica (1). Sendo o centro de convergência dos meios naturais de comunicações - estradas e rios - a cidade serviu como um entreposto para o comércio de sua região, como ponto de intercâmbio entre o litoral e o planalto. Com o aumento do cultivo do café em meados do século XVIII, sua predominância foi ameaçada. Localizado nos arredores de Campinas, Piracicaba, Capivarí, Porto Feliz, Itú e Mogí Mirim, o comércio do café foi se transladando e passou a ser feito através do Rio de Janeiro (2). Campinas, então, tornou-se rival da hegemonia de São Paulo, chegando-se a cogitar da mudança da capital para lá (3). Entretanto, na década de 1870, São Paulo iniciou um grande surto de desenvolvimento que deixou todos os possíveis rivais muito para trás. As antigas terras de plantação de café

(*). - $\mathrm{O}$ autor, candidato ao doutoramento na Indiana University, agradece a Doherty Foundation da Princeton Lniversity a bolsa de estudos para a sua pesquisa no Brasil. Bem assim aos Professores Sérgio Buarque de Holanda e Antônia Fernanda Pacca de Almeida Wright pela gentileza em dar, tão livremente, conselho e ajuda. À Professora Fernanda um voto especial de agradecimento por sua atenção aos problemas de um pesquisador estrangeiro.

(1). - Prado Júnior (Caio), "Nova contribuição para o estudo geográfico da cidade de São Paulo", Estudos Brasileiros, Ano III, v. 7, 1941, p. 203 . 25-1-1909.

Pestana (Paulo), "A metrópole paulista", em Estado de São Paulo,

(2). - Prado Júnior (Caio), "O factor geográfico na formação e no desenvolvimento da cidade de São Paulo", em Evolução politica do Brasil $e$ outros estudos, Editora Brasiliense Ltda., São Paulo, 1953, p. 115.

(3). - IBGE, Conselho Nacional de Estatística, Synopse estatística do Município de São Paulo, Serviço gráfico do IBGE, Rio de Janeiro, 1950, p. 5. Geiger (Pedro Pinchas), Evolução da rede urbana brasileira, Centro Brasileiro de Pesquisas Educacionais, Instituto Nacional de Estudos Pedagógicos, Ministério da Educação e Cultura do Brasil. Rio de Janeiro, 1963, p. 195. 
exauriram-se e novas áreas de cultivo surgiram no norte e no oeste. Mais uma vez, a posição geográfica de São Paulo foi o principal fator da consolidação da proeminência econômica da cidade, visto que esta foi o centro natural de arrecadação para as novas terras (4). Desta vez, porem, acrescentou-se, ao poder de atração da cidade, um novo aliado: a estrada de ferro. Começando em 1867 com a Santos-Jundiaí, São Paulo tornou-se o fulcro de irradiação de uma rede ferroviária, tornando-se a única cidade de facil acesso da região, alem do local exato de confluência para as exportações destinadas ao porto de Santos (5). A indústria e a imigração estrangeira, dois novos fatores adicionais - ambos relacionados com café e ferrovias - tambem serviram inicialmente como auxílio, e depois, para consolidar a supremacia da cidade (6). De uma população de $26.040 \mathrm{em} \mathrm{1872,}$ São Paulo cresceu para $47.697 \mathrm{em} 1886$ e 64.934 em 1890. Estes expressivos algarismos eram apenas um prelúdio. Em 1893 a população da capital somou 130.775 e em 1900, 239.820 (7).

A importância preponderante da estrada de ferro como causa e expressão do crescimento de São Paulo, é assunto que naturalmente atraiu a atenção de uma grande quantidade de estudiosos.

Um outro tipo de comunicação, o transporte urbano, não tão comentado, mas ainda assim importante, tambem atingiu e refletiu o desenvolvimento da cidade. Certamente os estudiosos de urbanismo atribuem papel decisivo aos transportes urbanos na estruturação do plano do crescimento de uma cidade, pois aqueles forjam o tão necessário elo de ligação física entre um centro urbano e seus subúrbios próximos, permitindo que existan diferenciações funcionais espacialmente

(4). - Prado, "O factor geográfico", op . cit., p. 116.

(5). - Bandecchi (Pedro Brasil), "São Paulo, de cidade provinciana à metrópole", em Curso de História de São Paulo. Prefeitura do Município de São Paulo, Secretaria de Educação e Cultura, Divisão do Arquivo Histórico, São Paulo, 1969, pp. 167-168.

Prado, "O factor geográfico", op. cit., p. 117.

Singer (Paul), Desenvolvimento econômico e evolução urbana; análise da èolução econômica de São Paulo, Blumenau, Porto Alegre, Belo Horizonte e Recife. Editora Nacional. São Paulo, 1968.

(6). - IBGE, op. cit., p. 5.

(7) . - Pestana (Paulo), "Estudos demographicos. A populạão da capital paulista. Seu crescimento pelos diversos recenseamentos. Um calculo acceitavel para a actualidade" em Estado de São Paulo, 13-3-1908. Todos estes algarismos são de recenseamentos: 1872, censo geral; 1886, censo provincial; 1890 , censo federal; 1893 , censo estadual; 1900 , censo federal. Mesmo não sendo rigorosos, os vários recenseamentos são adequados para dar uma idéia do desenvolvimento da cidade. Para 1908, Pestana calçulou uma população de mais de 330.000 . 
definidas dentro da própria cidade (8). Os diversos processos que definem a maneira de dispor-se do espaço de uma cidade - concentração, centralização, segregação, invasão e sucessão - são geralmente determinados pelos padrões de transportes que neles existem (9). Conforme uma cidade cresce em população e extensão, a necessidade de locomover pessoas e bens dentro da cidade e suas imediações tornam-se mais prementes e complexas. A produção primária e a agricultura de subsistência progressivamente são abandonadas dentro dos limites da cidade por causa da importância crescente de ocupações como comércio, indústria e das demais atividades secundárias e terciárias que surgem com a urbanização (10) . A cidade, portanto, transforma-se em algo semelhante a um parasita que se mantem através da produção agrícola das zonas vizinhas. Ao mesmo tempo, diferenciações funcionais dentro da cidade, o crescimento de áreas distintas como, centro comercial, área industrial e zona residencial, aumentam a necessidade de meios eficientes de conquista de espaço para que se interliguem estas várias zonas (11). De luxo que era o transporte urbano passa a ser uma necessidade vital. Tal foi o caso com São Paulo.

Em 1872 São Paulo recebeu seus primeiros bondes, uma linha ligando o centro da cidade com a Estação da Luz (12), construida pela Companhia Carris de Ferro de São Paulo. Com o crescimento da ci-

(8). - Davis (Kingsley) e Golden (Hilda Hertz), "Urbanization and the Development of Pre-Industrial Areas", em Hatt, Paul K. e Reiss, Albert J. Jr., Cities and Society. The Revised Reader in Urban Sociology. The Free Press. Glencoe, III., 1957, p. 138. Mayer (Harold M.), "A Survey of Urban Geography", em Hauser (Philip) e Schnore (Leo), The Study of Urbanization.

John Wiley \& Sons. New York, 1965, p. 94.

(9). - Hatt and Reiss, op. cit., p. 233.

Hatt and Reiss give the following definitions: Concentration is the process whereby a settlement appears and grows. It describes changes in the size of pcpulation agglomerations, usually involving a change in the density of settlement. Centralization is the process by which the various productive, distributive and service functions of a city group in relatively permanent locations. Segregation is the process whereby people and their institutions are sifted and sorted by a variety of factors-social and economic-in such a way that concentration of similar land uses and population types appear. Invasion ocurrs when a new type of land use or population intrudes into a previously established zone. When this invasion culminates in the establishment of a new type of alea, it is called succession. Ibid, pp. 223-226.

(10). - Geiger, op. cit., p. 61 .

(11). - Johnson (James H.), Urban Geography, An Introductory Analysis. The Commonwealth and International Library. Pergamon Press. Oxford, $1967, \mathrm{p} .38$.

(12). - Nogueira de Matos (Odilon), "São Paulo no século XIX", è Azevedo (Aroldo de) e outros, $A$ cidade de São Paulo, Estudos de geografia urbana por um grupo de geógrafos sob a direção de Aroldo de Azevedo. Associação dos Geógrafos Brasileiros. Secção Regional de São Paulo. Companhia Editora Nacional. São Paulo, 1958, V. p. 93. 
dade, outros empreendedores, pressentiram, na necessidade crescente de transportes, uma oportunidade para lucrar, solicitando, ou requerendo, concessões similares. Na verdade, tanto as autoridades da cidade, como das províncias, se viram crivadas de pedidos para grandes zonas de privilégio. A maioria de tais pedidos nunca vieram a ser realizados. O contrato da Companhia Carris de Ferro com a Província, concedia 50 anos de privilégio exclusivo para o estabelecimento de bondes entre o centro da cidade e as estações de trem e subúrbios. Revelou-se este contrato o principal obstáculo a outros dos muitos possíveis competidores, porquanto o Governo Provincial recusou vários desses pedidos por estarem os mesmos em conflito com a zona autorizada pertencente à Companhia (13). Tambem, muitas permissões quando concedidas nunca foram levadas a termo (14). Apesar disso, várias novas companhias surgiram, a princípio apenas ameaçando e, posteriormente, destruindo o antigo monopólio da Companhia Carris de Ferro.

Em 1880 o Engenheiro Alberto Kuhlmann recebeu uma concessão de 25 anos para abrir uma linha para a Vila de Santo Amaro, formalizada num contrato de 14 de junho de 1883 entre a Província e a "Companhia Carris de Ferro São Paulo à Santo Amaro" (15). Em 1889 Victor Nothmann e Fernando Dumoulin firmaram um contrato com a Província, para duas linhas de bonde que sairiam do centro da cidade e iriam para os bairros de Bela Vista e Bom Retiro, e organizaram a Companhia Ferro Carril para se encarregar desse serviço

(13). - Por exemplo, em 27 de abril de 1886, o Presidente da Província negou uma concessão a Godofredo José de Piedade, Carlos Americano Freire e Henrique Wright, para uma linha de bondes partindo do Largo do Paissandú para a Freguesia do $\sigma$, devido a ser esta uma parte da zona da Companhia Carris de Ferro. E antes disso, em 15 de fevereiro e 25 de junho, o governo provincial aprovou um recurso da Companhia Carris de Ferro contra uma concessão feita pela Câmara Municipal de São Paulo para uma linha do centro da cidade para o Ipiranga, com o mesmo fundamento. Relatório apresentado à Assembléa Legislativa Provincial de São Paulo pelo presidente da província Barão do Parnahyba no dia 17 de janeiro de 1887. Typographia a vapor de Jorge Seckler \& Comp.. São Paulo, 1887, p. 90.

(14) . - Por exemplo, em 1890, o engenheiro da Intendência de São Paulo, Luiz C. do Amaral Gama, informando sobre dois pedidos para estabelecer linhas de bondes de Ponte Grande à Serra da Cantareira, passando por Sant'Ana, com um ramal para o $O$, observou que a concessão fora dada aos irmãos Silveira da Motta, "há tempos", mas eles ainda não tinham começado obra alguma. Arquivo Municipal (daqui para diante, AM), Papeis Avulsos, 1890, vol. 17, s.n. Luiz C. do Amaral Gama a Clementino de Souza e Castro, 25 de maio de 1890 .

(15). - Arquivo do Estado de São Paulo (daqui em diante, ASP), Relatórios Diversos, 1864-1885, № 5652, caixa 1. Relatório de Eugênio da Silva, engenheiro fiscal da Companhia Carris de Ferro São Paulo a Santo Amaro, 1885 . 
(16). Por volta de 1890 , São Paulo ostentava onze diferentes linhas de bonde servindo, ou planejadas para servir, a própria cidade, bem como áreas da redondeza como Sant'Ana e a Freguesia do $O$ (17).

Em muitos pontos, no entanto, as melhorias na comunicação asseguradas por estas companhias se tornaram ilusórias. Empenhados em um conflito prejudicial para ambas as partes, e extendendo áreas de privilégio, as companhias, inicialmente elogiadas pela imprensa e pelo povo como fontes de progresso, gradativamente vieram a ser criticadas pelas suas atitudes grosseiras face às necessidades públicas. Por conseguinte, em 1890 Guilherme M. Rudge, concessionário de uma linha de bondes para Penha, Luz e Moóca, reclamou à Câmara Municipal de São Paulo que estava sendo ameaçado por pretenções da Companhia Carris de Ferro. Embora a concessão de Rudge datasse de 1883, as tentativas da Companhia Carris para obter preferência suspensa, baseou-se na incapacidade de Rudge em construir suas linhas. Contudo, a Companhia Carris tampouco as construiu. $\mathrm{Na}$ verdade, provou Rudge, o direito da preferências

$$
\begin{aligned}
& \text { "... tem-se reduzido a simples e repetidas reclamações, e a } \\
& \text { nada construir" (18). }
\end{aligned}
$$

De maneira parecida, ocorreram conflitos amargos entre a Companhia Carris e a Companhia Ferro Carril. Em 1889 quando Nothmann e Dumoulin receberam seu contrato, a Companhia Carris objetou que isto era uma violação de sua zona de privilégio. Enquanto o caso ainda estava sem uma decisão, a Companhia Carris pediu autorização para modificar algumas de suas linhas existentes e para estabelecer várias linhas novas, entre elas a linha para o Bom Retiro. Em 2 de agosto de 1889, o Governo Provincial recusou proteger as reivindicações da companhia que as zonas tinham sido invadidas, e permitiu que Nothmann e Doumoulin assinassem o contrato. Apesar desta decisão, em 9 de agosto de 1889 o Presidente Provincial, General Couto de Magalhães, autorizou, sem injurias à terceiros, os pedidos de modificações e novas linhas da Companhia Carris. Por con-

(16). - ASP, Secretaria da Agricultura, Ofícios Diversos, 1890, No 4.130, caixa 10. 20, janeiro, 1890, Palácio do Governo do Estado de São Paulo, Prudente J. M. Barros.

(17). - Diário Popular, 28-2-1890. As onze eram as linhas de Bom Retiro e Bela Vista (Ferro Carril), Companhia Carris de Ferro, Linha da Penha, Carris Urbanos nos circulares para cargas. Vila Mariana (Ramal do Matadouro da Companhia Santo Amaro), Linha Aérea, Linha Ypiranga, Linha Perdizes, Linha Circular, Linha de Ponte Grande a $O$, e os bonds de Sant'Anna.

(18). - (AM, Papeis Avulsos, 1890, vol. 15, s.n.). Guilherme M. Rudge aos Cidadãos Intendentes, 2, julho, 1890. 
seguinte, ambas as companhias acreditaram que tinham o. direito de servir o Bom Retiro, e ambas começaram a colocar os trilhos. O resultado foi uma briga entre os trabalhadores das duas companhias e futuras apelações para a Justiça. No ano seguinte, Prudente de Moraes Barros, como chefe do governo do Estado, resolveu o caso, e decidiu a favor da Companhia Ferro Carril (19). A decisão de Prudente no entanto, não resolveu todos os conflitos entre as duas companhias. Derrotada na linha para o Bom Retiro, a Companhia Carris interpôs um embargo judicial contra a linha Ferro Carril para Bela Vista. E claro que, enquanto a batalha legal estava sendo travada, os trilhos não estavam sendo colocados, razão porque a linha para Bela Vista não foi aberta até 13 de dezembro de 1891 . Mais tarde, por volta do fim de 1891, a Companhia Ferro Carril ainda não havia colocado todos os desvios e nem apresentado uma previsão definitiva (20). Os hatantes de Bela Vista, um tanto ironicamente, observavam que o progresso de seu bairro foi tão grande que desde 1888 duas companhias tinham disputado o direito de servi-los, com o resultado infeliz que a introdução da melhoria desejada tinha sido retardada (21). Rixas como essas se tornaram uma fonte de queixas públicas, e resultou que o governo municipal de São Paulo convocou uma reunião de representantes de todas as linhas urbanas de bondes (22). Clementino de Souza e Castro, Presidente do Conselho da Intendência, apontando para os problemas surgidos com reclamações conflitantes alegando os

(19) . - ASP, Secretaria da Agricultura, Ofícios Diversos, 1890, N9 4.130, caixa 10. Prudente, op. cit . ao dar o parecer a favor da Cia. Ferro Carril, Prudente observou que a intenção do Governo Provincial ao dar o contrato à Cia. Carris não era a criação de uma zona privilegiada a respeito de todas as linhas possíveis em todas as direções do centro da cidade aos subúrbios, mas só para as linhas efetivamente estabelecidas.

(20). - Relató io apresentado pela Superintendência de Obras Públicas do Estado de São Paulo em 31 de março de 1892 ao cidadão Dr. Alfredo Maia, Digno Secretario dos Negocios d'Agricultura, Commercio e Obras Publicas deste Estado, p. 45.

(21). - ASP, Secretaria da Agricultura, Ofício Diversos, 1891, No 4.132, caixa 12. 3 de junho de 1891 , representação de oitenta e dois moradores de Rua Formosa, Largo do Riachuelo, ruas Santo Antônio, Misericórdia, São Domingos, Conselheiro Ramalho e bairro de Bela Vista. E interessante notar que ao mesmo tempo que a Companhia Ferro Carril protestou contra o monopólio da Companhia Carris, aquele reclamou contra concessões feitas ao Alberto Kuhlmann, Abílio Soares e outros por estar em conflito com a zona garantida pelo contrato de 13 de março de 1890 . Veja ASP, Intendências Municipais, 1889-1891, No 5.543, caixa 4. 5 de setembro de 1890. Paço da Intendência Municipal de São Paulo.

(22). - A reunião teve lugar em 28 de fevereiro de 1890, e foi assistida por representantes de tudas as companhias, meros a linha de Ponte Grande a O e os bonds de Sant'Anna. Veja Diário Popular, 28 de fevereiro de 1890. 
mesmos privilégios, sugeriu que um plano deveria ser estabelecido de maneira a criar harmonia entre os concessionários. Uma comissão de profissionais foi formada e incumbida de estudar o sistema de transporte urbano (23). Não resultou disso melhoria imediata, e no ano seguinte o vereador Fernando Albuquerque observou o mesmo problema, ou seja, a divergência proveniente de direitos existentes entre as várias companhias, as quais provocaram dificuldades cotidianas com a colocação dos trilhos causando grande dano ao transito e conforto do público (24). Não somente o público sofreu. As companhias como recompensa receberam uma grande dose de desastres financeiros. Reconhecendo que tal negócio não poderia continuar, em 1891 várias outras companhias se fundiram para formar uma nova entidade, a Companhia Viação Paulista (25). Conforme seu relatório de 1893 , a motivação para esta nova companhia foi o desejo de amenizar os conflitos e custos e por esse meio dar melhor compensação aos acionistas. As duas companhias que se mantiveram aparte da fusão, a "Empresa de Bondes de Sant'Ana" e a "Companhia Ferro Carril", entretanto, fizeram um acordo de trabalho com a "Viação Paulista", de maneira que agora havia uma unidade substancial para o sistema de São Paulo de transporte urbano (26).

Embora as companhias pensassem que a fusão seria uma solução fundamental para evitar a discussão e perda de rendimento, o passo final para consolidar uma posição rendosa provou não ser mais que um expediente temporário, tanto para seus interesses privados como para os interesses públicos. Em 1894 o estado crítico da Viação Paulista teve uma repercução na imprensa que não constituia novidade: trilhos ruins, vagões inadequados em funcionamento, animais e pes-

(23). - Idem.

(24). - Atas da Câmara Municipal (Conselho da Intendência) de Säo Paulo, 1891. Typ. Espindola, Siqueira \& Comp.. São Paulo, 1905, p. 104.

(25). - Relatório da directoria da Compania Viação Paulista apresentado á assembléa geral de accionistas em 10 de marco de 1893. Typ. de Hennies \& Winiger, São Paulo, 1893. A força que motivou a organização de nova entidade era a Companhia Carris de Ferro. Incluiu a Viação Paulista companhias de Santos além de São Paulo. Um elemento importante em São Paulo era a Companhia Paulista de Transportes, que já tinha absorvido várias linhas como as de Ipiranga, Mercado a Moóca, Aterrado e Rua do Brás. Em 30 de junho de 1890 a extensão das linhas da Companhia Carris estava 27.963,00 metros. A Companhia Paulista de Transportes deu mais 13.355,00 metros. Além disso, na formação da Viação Paulista houve fusão da Companhia Carris a Companhia Santo Amaro. Estatutos da Companhia Viação Paulista, Cia. Impressora, Rio de Janeiro, 1891, p. 3. De fato, Alberto Kuhlmann passou a ser gerente da Viação Paulista. Porem, como não foi o caso com as outras companhias que faziam parte da fusão, a Companhia Santo Amaro mantinha sua própria identidade, e, parece, seus próprios interesses fora da fusão.

(26). - Ibidem. 
soal inferiores, tudo era criticado nos jornais, mas sem resultado. Isso era mais irritante, disse o Intendente de Obras, desde que o transporte urbano

"já constitue uma necessidade imprescindivel para a nossa população" (27).

Mais perigoso para a Viação Paulista, do que a crítica pública no entanto, foi o aparecimento de um novo rival: The São Paulo Tramway, Light and Power Company. Em 1897 o Comendador Antônio Augusto de Souza e o Capitão Francisco Antônio Gualco receberam uma concessão da Câmara Municipal para estabelecer linhas para bondes elétricos (28). A impossibilidade de reunir capital necessário impediu o começo da construção, e, em 1899, eles transfieriram seus direitos para a Canadian Corporation, a São Paulo Railway, Light and Power Company (29). Dentro de um pequeno espaço de tempo, essa nova empresa eliminou toda competição. Por sentença judicial em 15 de março de 1900, o total acervo da Companhia Santo Amaro foi posto em hasta pública e adquirido pela Light. Com as ações da Companhia Paulista aconteceu o mesmo fato, entraram em liquidação forçada e foram compradas pela Light em ação pública em 27 de abril de 1901. Finalmente, em 1907 os bondes para Sant'Ana foram incorporados na concessão da Light (30). Os vários temas sugeridos nessa breve visão do início da história do transporte urbano em São Paulo tornam-se mais claramente definidos ao fazer-se o exame de uma empresa específica, como a "Companhia Carris de Ferro e Santo Amaro". Todavia esta companhia não era inteiramente

De fato, em 1893, o engenheiro fiscal, A. Lopes de Leão observou que as Companhịas Viação Paulista e Ferro Carril eram "fundidas". A. Lopes de Leão ao Intendente de Justiça e Polícia da Câmara Municipal, Papeis Avulsos, 1893, vol. 4, 21-2-1893. AM.

(27). - Relatório annual da seç̧ão de obras da Intendência Municipal de São Paulo, 1894. Apresentado ao cidadão Cesario Ramalho da Silva, M. D. Intendente Municipal por J. F. Ortiz, Engenheiro-Chefe Interino. Typ. Espindola Siqueira \& Comp., São Paulo.

(28). - Lei 304,15 de junho de 1897. Leis, resoluções, actos $e$ actos executivos da Câmara Municipal da Capital do Estado de São Paulo, de 1897-1899. Casa Vanorden. São Paulo, 1916, pp. 7-8.

(29). - The São Paulo Tramway Light and Power Co., Limited, Cinqüenta anos com São Paulo, 1900-1950, s.d., p. 2. Os sócios eram James Gunn, Alexander Mackenzie, Herbert Vernon, John Smith, Archibald Sinclair, Richard Gosset e Ernest McNeil. O nome da companhia mudou-se para evitar confusão com a São Paulo Rálway Company.

(30). - Memorial sobre o serviço de transporte colectivo apresentado à Câmara Municipal de São Paulo pela The São Paulo Tramway, Light \& Power Co. Limited, 1927, p. 3. 
uma linha urbana, pois Santo Amaro era então uma vila independente, a sua razão real de ser era baseada no crescimento de São Paulo como centro de consumo. Por volta de 1885 Santo Amaro já era um importante fornecedor para o mercado de São Paulo, para onde se enviava grande quantidade da farinha de mandioca e polvilho, como tambem pequenas quantidades de feijão, milho e batatas (31). Alem disso era uma importante fonte de lenha.

Até então, a linha de Santo Amaro fora planejada para ser estritamente condutora de carga, seus lucros viriam de um reforço do já importante laço de comércio entre a vila e a cidade.

Logo depois de assegurar seu contrato, a companhia começou a trabalhar, e a primeira seção da linha, de três quilômetros de extensão, de São Joaquim para Vila Mariana, foi aberta ao tráfego em 25 de janeiro de 1885 (32). O horário inicial era amplo. Os carros para Vila Mariana foram estabelecidos entre o horário de 6:40 e 8:40 com intervalos de aproximadamente uma hora. Na direção oposta havia carros correndo entre 6:20 e 8:40 com o mesmo intervalo (33). Grandes esforços foram feitos para refinar e melhorar o serviço. Em fevereiro de 1885 a companhia anunciou que, para reduzir o tempo de viagem em dias de mau tempo, teriam bondes extras nos dias de semana à tarde para permitir aos passageiros da linha da Companhia Carris de Ferro da Liberdade fazer uma conexão para Vila Mariana (34). Por volta do fim do ano os trabalhos estavam completos até Santo Amaro, estações estabelecidas e o projeto oficial de inauguração da linha completa para março de 1886 (35). Igualmente impressionante era a rápida substituição da força animal pela força de vapor na primeira seção. As locomotivas do sistema Krauss de Munique, Bavária, iguais às usadas nas principais cidades européias, chegaram a São Paulo em novembro de 1885 (36), e começaram a funcionar no mês seguinte. No primeiro dia da tração a vapor, 13 de dezembro de 1885 , umas 3.500 pessoas tiraram vantagem da novidade, o primeiro bonde de São Paulo a usar sistema de locomoção sem ser a força animal (37).

(31). - (AM), Gêneros entrados no mercado, 1885. Livro 2, No 1.305 .

(32). - Relatório apresentado à Asscmbléia Legislativa Provincial de São Paulo pelo Presidente da Província João Alfredo Corrêa de Oliveira em 15 de fevereiro de 1886. Typ. Jorge Seckler \& Comp., 1886, p. 7.

(33). - Diário Popular, 29-1-1885.

(34). - Idem, 9-2-1885.

(35) - Relatorio... d Assembléia Legislativa Provincial, 15 de fevereiro de 1886, op. cit., p. 78.

(36) . - Diário Popular, 21-11-1885.

(37). - Idem, 14-12-1885. 
Durante os primeiros oito meses de funcionamento da companhia ela transportou 16.675 passageiros (38).

Revendo este período inicial de operação, o engenheiro fiscal do Estado observou que houve diminuição de passageiros durante o periodo junho-outubro em consequência do tempo frio e da falta de atrações em Santo Amaro para pessoas gozando férias, a não ser pelo bom ar e passeios no campo. Entretanto, continua ele, aos domingos e dias Santos o movimento era de 800/1.000. Alem do mais, apesar de haver um padrão periódico para o tráfego de férias, o tráfego dos dias úteis apresentou um crescimento regular. Como indício posterior da boa fé da companhia e do desejo de servir, ela concedeu passagem grátis para escolares (39), e, em seguida à inauguração do sistema a vapor, o preço de São Joaquim para Vila Mariana foi reduzido de 200 para 100 réis (40). No prazo certo, em 14 de março de 1886 , a inauguração oficial da linha completa, $19 \mathrm{~km}$ e $120 \mathrm{~m}$, realizou-se (41). Alem da primeira seção para Vila Mariana, havia agora seções para Encontro, Volta Redonda e Santo Amaro, continuando até o terminal no ponto da Vila. Concomitante com o aumento em extensão foi o aumento de passageiros. No período de agosto a outubro de 1886 a média diária foi de 446,67 (42). A despeito desse começo auspicioso, os primeiros anos da companhia não foram sem problemas. Mostrando um desejo prematuro de expandir-se alem dos limites de seu contrato original, a companhia pediu à Província uma autorização para construir um ramal de Vila Mariana para o local onde a Câmara Municipal construiria o novo matadouro municipal. Em 9 de abril de 1885 , a lei Provincial $n^{\circ} 89$ confirmou esse novo privilégio (43). Ao mesmo tempo a companhia fez um contrato com o Município para construir o matadouro no Rincão do Sapateiro. Este concessionamento do transporte da carne, ainda que fosse bom negócio, provocou uma reação desfavoravel do público. Muitos negociantes de carne verde obetaram contra o local proposto. Baseando suas reclamações no relatório do físico da Câmara Municipal, Dr. Eulálio da Costa Carvalho, eles enumeraram os vários defeitos do Rincão: inundações periódicas, falta de pastagens adequadas e água. Reconhe-

(38). - (ASP, Relatórios Diversos, 1864-1885, No 5.652, caixa 1). Relatório de Eugênio da Silva, op. cit; desde total, 9.191 eram gratuitas, inclusive 3.487 para estudantes.

(39). - Idem.

(40). - Diário Popular, 10-12-1885.

(41). - Relatório apresentado à Assembléia Legislativa Provincial de São Paulo, 17 de janeiro de 1887 , op . cit., p. 91 .

(42). - Idem, p. 92.

(43). - Lei 89,9 de abril de 1885. Leis Provinciaes, 1885, p. 41. 
cendo que o Rincão era muito perto da cidade, então eles preferiram o local do Rio Pequeno. Todavia, disseram os negociantes, a maior velocidade dos trens da Sorocabana eliminaria qualquer diferença de tempo (44). Apesar de tais protestos, a Câmara resolveu manter o contrato com a Companhia Santo Amaro (45). Embora a companhia tenha assegurado uma concessão favoravel, ela envolveu-se em negociações políticas e provocou suspeita. Inicialmente, mais danosos do que gracejos com a fé pública foram os problemas da companhia com uma rival ciumenta, a Companhia Carris de Ferro. De maneira a fazer seus negócios de carga mais viáveis a Companhia Santo Amaro quis estender essas linhas de carga para as estações da estrada de ferro e para o mercado municipal. Antecipando que seria capaz de alcançar um acordo com a Companhia Carris, a Companhia Santo Amaro usou a mesma bitola cmpregada por aquela companhia, embora isso aumentasse suas despesas. A Companhia Carris, no entanto, recusou qualquer acordo, embora tal acordo os provesse de lucros extras e sem despesas. O engenheiro fiscal enfatizou a necessidade para um acordo indicando que Santo Amaro era:

\footnotetext{
"chave de um distrito de mais de 12.000 habitantes, mais da metade do fornecimento de víveres, madeiras, lenha, pedras, etc. etc., gasto na capital" (46).
}

A linha de Santo Amaro, até então, deveria ser capaz de estender seus trilhos até perto da cidade.

A atitude da Companhia Carris era típica, manter a zona de prilégio a todo custo. Assim, não foi senão antes de 1887 que a Companhia de Santo Amaro obteve o direito de transitar para o Mercado (47).

Dentro de um curto tempo problemas como estes tornaram-se regra, e a boa sorte da companhia evaporou-se. Por volta de janeiro de 1888 a companhia foi forçada a pedir um aumento das passagens, porque ela não teve sequer um semestre em que a receita ultrapassasse as despesas. Foi pedido para dobrar o preço da passagem de São

(44). - Diário Popular, 6-10-1885.

(45). - Atas da Câmara Municipal de São Paulo, 1885.

(46). - (ASP, Relatórios Diversos, № 5652, caixa 1). Relatório Eugênio da Silva, op. cit.

(47). - Exposição com que o exm. snr. Visconde do Parnayba passou a administração da Província de São Paulo ao exm. Dr. Francisco de Paula Rodrigues Alves, Presidente desta província no dia 19 de novembro de 1887. Typ. de Jorge Seckler \& Comp., São Paulo, 1885, 'p. 101. 
Joaquim para Vila Mariana, como resultado restabeleceram o preço da passagem para $\$ 200$ réis que fora o preço obtido na inauguração da linha (48). A despeito da morosidade de sua folha de balanço a companhia estava anciosa para expandir-se. Em 1890 requisitou duas extensões, uma de $20 \mathrm{~km}$ de Santo Amaro para Itapecerica, e outra uma extensão do ramal do matadouro alcançando Pinheiros. A companhia baseou ambos os pedidos no desejo de servir, canalizando toda a produção de Santo Amaro e Itapecerica através de suas linhas e desenvolvendo o serviço com as necessidades dos subúrbios da Capital (49). Não se considerando o público usuário, entretanto, estes pedidos eram um atentado para salvaguardar as zonas de privilégio da companhia, de uma outra companhia de bondes, porque a Companhia Rurícola Comercial tinha planos nessa área. De fato, esta última empresa fez uma petição à Província para uma concessão de 50 anos para uma linha de São Paulo à Capela de Pinheiros, e o requerimento foi considerado favoravelmente pelo superintendente de Obras Públicas. Alberto Kuhlmann, Diretor Superintendente da Companhia Santo Amaro, apressou-se em apontar que a petição de sua companhia para um privilégio similar antecedia àquela da Rurícola. De mais a mais, a Intendência de São Paulo havia previamente permitido a concessão para Abílio Soares e sócios para uma linha da cidade à Capela de Pinheiros, incluindo um ramal para o matadouro. A concessão de Soares foi transferida para a Companhia Carris de Ferro, e, através de um acordo com esta companhia, a empresa de Kuhlmann estava construindo o ramal. Na verdade, quase nove [9] quilômetros de trilhos já estavam colocados. Por isso, ele protestou que não deveria haver privilégio concedido a um terceiro (50). Obviamente havia uma sé-

(48) . - Companhia Carris de Ferro São Paulo à Santo Amaro ao Presidente da Província, 19 de janeiro de 1888. (ASP, Obras Públicas, 1888, No 5199 , caixa 62 , pasta 1 , documento 17 ). A Companhia pediu o seguinte: Nas três seções ertre Vila Mariana e Santo Amaro $\$ 300$ réis por seçâo em vez de $\$ 200$; de São Joaquim à Santo Amaro, $1 \$ 500$ réis em vez de $1 \$ 000$; nos dias úteis a tarifa de $\$ 100$ réis entre Vila Mariana e o matadouro seria mantido; Continuará tendo carros especiais para "descalçados", mas, sem a atual tarifa reduzida. Informando sobre o pedido, 27 de janeiro de 1888, a Diretoria Geral de Obras Públicas assinalou que estas tarifas ainda eram menos que as máximas estipuladas no contrato de 1883 , e, por isso não tinha nada a opor. Porem, continuou, nos interesses de equidade, a tarifa para descalçados deveria ficar mais barata para cumprir o espírito daquele contrato que visava ajudar as classes menos favorecidas.

(49). - José Duarte Rodrigues ao Governador de São Paulo, 6 de maio de 1890. Obras Públicas de 1888-1891, № 5206, caixa 69, pasta 1, documento 58. ASP.

(50). - Presidente da Companhia Carris de Ferro São Paulo à Santo Amaro ao Governador de São Paulo, 12 de julho de 1890. Alberto Kuhlmann ao Governador do Estado, 7 de maio de 1891. Obras Públicas, 1888-1891, No 5206, caixa 69 , pasta 1 , documento 67 . ASP. 
ria falta de comunicação e coordenação, ambas entre a província e a municipalidade, e dentro do próprio governo provincial. Este problema de desentendimento entre as autoridades governamentais continua a criar dificuldades para a Companhia de Santo Amaro. Em 28 de agosto de 1891 o presidente da companhia, José Duarte Rodrigues, explicou que o novo ramal do matadouro para o Aterro do Gazômetro não seria terminado na data planejada de 3 de setembro de 1891 . Muitos problemas surgiram: demora inesperada na chegada de novas locomotivas, dificuldade em transportar pedras britadas e aquisição de dormentes, um processo de desapropriação contra Benedito José dos Mercês. Mas o problema mais sério foi que por diversos meses o Presidente da Intendência havia impugnado o trajeto através da várzea do Carmo, dizendo que isto interferia com trabalhos projetados de saneamento. Embora a companhia tenha solicitado um traçado diferente através da várzea, assim mesmo a Intendência não tomou nenhuma decisão (51). Ainda outra autoridade local interferiu com os planos da companhia. A Intendência de Santo Amaro opôs-se a ter trilhos colocados do outro lado do atual terminal da estação. Esta prevenção perdurou por muito tempo. Em 1885 a Câmara Municipal ainda não queria que a linha do terminal da estação fosse no centro da vila. Titulando o incidente como: "Santo Amaro não quer progresso", o Diário Popular explanou esta relutância:

\footnotetext{
"porque não compreende a dita Câmara que as mansas locomotivas da empresa Kuhlmann entrem no povoado" (52).
}

Agora, seis anos mais tarde, em 30 de setembro de 1891, como resposta a um requerimento da Intendência Municipal de Santo Amaro, o governo Estadual ordenou à companhia para remover seus triIhos que iam ao centro da Vila, pois eles estavam interferindo com planos de expansão da Rua Tenente Adolfo que iria tornar-se uma avenida (53). Não estando inclinados a abandonar seus trilhos, a companhia relembrou ao Estado que o contrato de 1883 estipulava que o ponto do terminal da linha seria no centro da Vila (54). Finalmente um plano de acordo foi estabelecido pelo qual a companhia receberia um novo traçado, mas os velhos trilhos seriam removidos so-

(51). - José Duarte Rodrigues ao Presidente do Estado de São Paulo, 28 de agosto de 1891 . Secretaria da Agricultura, Ofícios Diversos, 1891, No 4.131, caixa 11, ASP.

(52). - Diário Popular, 30-11-1885.

(53). - Relatório apresentado pela superintendência de obras públicas, 1892, op. cit., p. 46.

(54). - José Duarte Rodrigues a Américo Braziliense, 13 de outubro de 1891. Secretaria da Agricultura, Ofícios Diversos, 1891, No 4.131, caixa 11, ASP. 
mente depois que os novos estivessem colocados (55). Entretanto, uma vez mais a exigência de uma autoridade local causou à companhia atraso e aumento de despesas.

Se a companhia tivesse sido interrompida por ações do governo municipal de São Paulo e Santo Amaro, decisões do governo do Estado teriam sido mais nocivas. Em 16 de outubro de 1891, engenheiros do Estado, Álvaro de Menezes e Arthur Assis de Oliveira Borges, fizeram uma inspeção de toda a linha. O relatório que eles submeteram, em 26 de outubro, ao Diretor de Obras Públicas foi muito prejudicial. Eles julgaram as seções de Vila Mariana para Santo Amaro e o ramal do matadouro como não sendo ruins, e este foi o comentário mais favoravel. Com referência ao tráfego pesado da primeira seção entre São Joaquim e Vila Mariana,

"difícil será encontrar-se uma linha suburbana com o tráfego pesado de todos os dias, em tão abandono por parte de sua administração como esta..." (56).

O material rodante era pesarosamente inadequado, quatro locomotivas velhas com tendência a executar um serviço deficiente e perigoso. Verdade é que a companhia tinha encomendado duas locomotivas novas, mas mesmo com estas em funcionamento o serviço não seria muito melhorado, e os engenheiros preveniram que em breve com a falta de material de tração seria impossivel para a companhia continuar seus serviços. Na verdade, assim mesmo o governo gozou o direito de ordenar modificações no horário para remediar insuficiências, e não havia dúvida que o presente horário era inadequado, mas as deficiências do material rodante era tal que nenhum serviço adicional poderia ser mantido sem riscos de acidentes. Para toda a linha havia apenas uma oficina e uma incrivel carência de pessoal. Cada estação originalmente tinha um agente em serviço, mas isto foi considerado dispensavel. Consequentemente, os usuários da linha tinham que embarcar e desembarcar suas próprias mercadorias. Alem do mais, as estações de Saúde, Encontro e Volta Redonda nunca foram abertas e, embora cada uma possuisse um telefone, não havia empregado presente para atende-lo. Isto resultou no que os engenheiros chamaram

(55). - Relatóio apresentado pela superintendência de obras públicas, 1892, op. cit., p. 47. Por portaria de 5 de dezembro de 1891, o governo estadual mandou tambem que a Companhia fornecesse uma locomotiva e três vagões para o movimento de terra da avenida; a Intendência de Santo Amaro pagaria os vencimentos do mecanista e foguista e as despesas com carvão e lubrificantes. Ibidem .

(56). - Diário Oficial, 31-10-1891. 
" $\mathrm{Na}$ passagem dos trens, o guarda de cada um deles desce, transmite $o$ aviso à próxima estação, e o comboio continua sen mais cuidados, a sua marcha" (57).

Álvaro de Menezes e Arthur Assis de Oliveira Borges propuseram várias medidas remediadoras a serem tomadas pela companhia, entre elas, reparo da primeira seção usando somente um tipo de dormente, lavagem dos vagões cada 30 dias e pintura cada seis meses, abrir todas as estações e colocar empregados. Quanto à ação do governo, eles propuseram uma multa de $30 \$ 000$ réis por dia, começando a partir de 17 de junho de 1891, até que o material rodante encomendado fosse posto no tráfego (58).

Submetendo o relatório dos engenheiros ao presidente do Estado, o Diretor de Superintendência de Obras Públicas, José Pereira Rebouças, afirmou que não tinha nenhum exagero. O mau estado da linha era,

\footnotetext{
"assaz conhecido do público que, continuadamente reclama, visto sofrer seu bem estar e sua comodidade..." (59).
}

Logicamente, a Companhia Santo Amaro não aderiu a este ponto de vista. Alberto Kuhlmann, depois de impugnar a habilidade e esmero dos engenheiros, alegóu que a companhia tinha feito grandes sacrifícios para servir o público. Apesar de todos os esforços nunca mostrou lucros. O governo devia reconsiderar, até então, instituindo medidas remediadoras (60). Esta justificativa do serviço público e sacrifícios financeiros deixaram Pereira Rebouças sem ação. Se a companhia tinha perdido dinheiro construindo o matadouro, isto era problema dela, para isso havia solicitado o contrato. No tocante à serviços públicos, a mistura da companhia de vários tipos de trilhos tornou impossivel ter material adequado de tração, isto numa linha que deveria suprir a capital com víveres. Alem do mais, o mal serviço da companhia em despachar produtos retardou o natural desenvolvimento das indústrias ao longo do leito da estrada (61). O governo até

(57). - Ibidem.

(58). - Ibidem.

(59). - José Pereira Rebouças a Américo Braziliense, 27 de outubro de 1891. Secretaria da Agricultura, Ofícios Diversos, 1891, No 4.138, caixa 18, ASP.

(60). - Alberto Kuhlmann a José Pereira Rebouças, 5 de novembro de 1891. Secretaria da Agricultura, Ofícios Diversos, 1891, № 4.137, caixa 17, ASP.

(61). - José Pereira Rebouças a Cerqueira Cesar, 17 de dezembro de 1891. Secretaria da Agricultura, Ofícios Diversos, 1891, No 4.137, caixa 17, ASP. 
então manteve sua atitude crítica e recusou anular as medidas adotadas depois do relatório de Borges e Menezes (62). Em parte, a forte resistência do governo refletiu na concientização da insatisfação pública. Por exemplo, em seguida a um acidente na seção para Vila Mariana (63), A Cidade de São Paulo acusava a companhia de fornecer um serviço que era completamente desleixado,

$$
\begin{aligned}
& \text { "tanto no pessoal da empresa, que é incompetente e relaxa- } \\
& \text { do, como no material rodante, que está todo estragado". }
\end{aligned}
$$

Obviamente, disse $A$ Cidade, as queixas contra a companhia não foram exageradas. $O$ Estudo de São Paulo comentou o incidente de dente de uma maneira bem mais mordaz. Referindo-se à companhia como:

$$
\text { "aquela vergonha dos trens da Vila Mariana", }
$$

e, criticando a administração da companhia, o leito da estrada e o material rodante, o artigo concluiu:

"A continuar assim o serviço será preferivel estabelecer-se uma linha de carros de boi, pouco mais rápidos que as locomotivas da Vila Mariana mas muito mais seguros" (64).

Em uma avaliação um pouco menos veemente, a Secretaria da Agricultura comentou que a linha poderia ser bastante util para suprir a capital com combustivel, materiais para construção e produtos de pequenas lavouras. Apesar do presente serviço da companhia estar longe de ser satisfatório, e vencendo condições econômicas, fez melhorias substanciais imediatas; o serviço da linha, se bem que vagarosamente, foi ficando melhor (65). A atitude otimista da Secretaria foi infundada, porque o mau serviço da companhia continuou. Dos habitantes de Santo Amaro vieram reclamações sobre o horário irregular e o mau estado dos vagões. Os defeitos da linha eram tais que, em uma curta corrida de São Joaquim para Vila Mariana, 'carros descarrilhavam três ou mais vezes (66). Ventilando reclamações similares, a Intendên-

(62) . - Relatório apresentado pela superintendência de obras públicas, 1892, op. cit., p.. 77.

(63). - O desastre aconteceu no dia 29 de novembro de 1891 .

(64). - José Pereira Rebouças a Cerqueira Cesar, 17 de dezembro de 1891, op. cit., Pereira Rebouça incluiu no ofício as reportagens dos dois jornais.

(65). - Relatório apresentado ao Dr. Vice-Presidente do Estado de São Paulo pelo Dr. Alfredo Maia, Secretário de Estado dos Negócios da Agricultura, Commércio e Obras Públicas. Typ. de Vanorden \& Cịa., São Paulo, 1892, p. 21.

(66). - "Santo Amaristas" ao Ministro da Agricultura do Estado de São Paulo, 17 de novembro de 1892, Secretaria da Agricultura, Ofícios Diversos, 1892 , No 4.150 , caixa 30 , ASP. 
cia de São Paulo obrigou o governo do Estado a tomar medidas para assegurar que a companhia preenchesse seu contrato (67). A companhia deu pouca atenção para tais reclamações. Sua principal preocupação foi em assegurar o aumento da passagem. Em junho de 1892, José Duarte Rodrigues, Presidente da Companhia, informou a Secretaria da Agricultura que o aumento de custo das operações forçou a companhia a requerer autorização para aumentar o preço de carga . Durante todos seus seis anos de operação a companhia tinha ainda que mostrar lucro. Em 1889, o presidente continuou e, depois de 3 anos de insucesso em competir com carros de boi, a companhia finalmente ganhou a maior parte dos serviços de carga por reduzir as taxas' em $60 \%$. A esta altura, entretanto, eles não tinham vagões suficientes para carregar toda a mercadoria. Presentemente, eles dispunham de meios suficientes de transportes, mas realidades financeiras tornaram-no impossivel lucrar a estes preços baixos. Duarte Rodrigues enfatizou que, como o maior propósito da linha era suprir a capital com lenha, mantimentos e outros materiais, seus serviços de carga tinham que ser a principal fonte de renda. Em face da pequena extensão da linha, em comparação com a estrada de ferro seu custo operacional por trajeto era correspondentemente mais alto. A única solução, até então, era reimpostar a tabela de carga que havia prevalecido em $1886(68)$.

Embora o aumento da taxa estivesse outorgado, não provou ser a solução esperada. No ano seguinte a companhia requereu ainda outro aumento. Desta vez, todavia, o governo do Estado não foi tão condescendente. Por mais de um mês aconteceu um choque de vontades entre os dois e na maioria deste tempo a linha de Santo Amaro não parou. Em abril de 1893 os primeiros sinais de problema infiltraram-se na Secretaria da Agricultura: quatorze comerciantes de São Paulo reclamaram do aumento excessivo nas taxas de carga de Santo Amaro

(67) - - Carlos Augusto Garcia Ferreira a Cerqueira Cesar, 26 de janeiro de 1892. Secretaria dá Agricultura, Ofícios Diversos, 1892, No 4.144, caixa 24, ASP. A Intendência reclamou tambem do péssimo serviço da Companhia no transporte e acondicionamento da carne vinda do matadouro municipal. Ibidem.

(68). - José Duarte Rodrigues a Secretaria dos Negocios d'Agricultura, Commercio e Obras Públicas, 4 de junho de 1892, Secretaria da Agricultura, Ofícios Diversos, 1892, No 4.143, caixa 23, ASP. Informando sobre este assunto, Arthur Assis de Oliveira Borges opinou que a nova tabela deve ser autorizada, mas que a Companhia por sua parte deve servir melhor o público para que termire as contínuas reclamações devidas às irregularidades do serviço. Arthur Assis de Oliveira Borges ao Diretor da Superintendência de Obras Públicas do Estado de São Paulo, 5 de julho de 1.892. Secretaria da Agricultura, Ofícios Diversos, 1892, No 4.143, caixa 23, ASP. 
para a Capital (69). Alguns dias depois a Câmara Municipal de Santo Amaro apresentou uma reclamação similar: violando seu contrato, a companhia havia dobrado as taxas cobradas (70). Documentando esta acusação, a Câmara apresentou uma petição que tinha recebido de cinquenta e três negociantes dizendo que, não obstante a companhia necessitasse aumentar as taxas de maneira a cobrir as despesas, a duplicação das tarifas estava alem dos limites da razão. Se esse nivel fosse mantido, preveniram os negociantes, o resultado seria a paralisação dos negócios de exportação (71). Não confiando somente nas ações do governo, os Santo Amarenses organizaram um boicote e recusaram embarcar qualquer material nos carros da companhia (72). Enquanto isso, mais reclamações surgiram nos jornais da capital, porque a companhia havia aumentado tambem os preços da taxa no ramal do matadouro (73). A companhia, contudo, foi intransigente, e ameaçou que, se o aumento nas taxas não fosse oficialmente concedido, encerrariam seus serviços.

Para justificar esta ação proposta, a companhia recorreu ao seu velho argumento; ela tinha feito grandes sacrifícios para servir o público, e nunca havia recebido uma recompensa financeira. Alem disso, a companhia afirmou que a falta de responsabilidade das autoridades governamentais havia forçado essa atitude e como prova dessa acusação eles publicaram dois ofícios que foram enviados antes do pensar em encerramento. Um, para o Diretor da Superintendência de Obras Píblicas, afirmou que a companhia tinha um enorme débito de $\mathbf{3 0 0}$ contos, uma quantia que igualava seu capital. Por esta razão, era impossivel comprar carvão ou reparar o equipamento. No segundo ofí-

(69) . - Abaixo assinado ao Secretario da Agricultura do Estado de São Paulo, 14 de abril de 1893. Secretaria da Agricultura, Ofícios Diversos, 1893, No 4.155, caixa 35 , ASP.

(70). - Presidente da Câmara Municipal da Vila de Santo Amaro a Jorge Tibiriçá, 20 de abril de 1893. Disse o Presidente que era bem conhecido que a "má gestão" dos negócios da companhia tinha prejudicado os interesses da própria companhia e trabalhado para o atraso da Vila, quando poderia ter sido o reverso. Secretaria da Agricultura, Ofícios Diversos, 1893, № 4.155, caixa 35, ASP.

(71). - Abaixo assinado aos Cidadãos e Mais 'Vereadores da Câmara Municipal, 19 de abril de 1893. A tabela 14 deu uma arifa por um vagão à Vila Mariana de $4 \$ 200$ réis, e a São Joaquim, $4 \$ 980$. Entretanto, a Companhia cobrava $9 \$ 000$ réis e $10 \$ 000$. Secretaria da Agricultura, Ofícios Diversos, 1893. No 4.155, caixa 35 , ASP.

(72). - Philippe P. Labarde a Bernardino de Campos, 21 de abril de 1893. Este avisou o Presidente do Estado que a greve na vila estava piorando, e que os aderentes dela não era gente bruta, mas "as pessoas grandes do logar". Por um vagão de 700 tijolos, os negociantes pagavam uma freta de $14 \$ 000$ réis - quatro vezes mais do que cobrava a "Inglesa" e a E. F. C. do Brasil. Secretaria da Agricultura, Ofícios Diversos, 1893, No 4.155, caixa 35, ASP.

(73). - Diário Popular, 4-5-1893. 
cio, enviado ao intendente geral da Câmara Municipal de São Paulo, essa argumentação de pobreza foi reinterada. O custo do frete entre o matadouro e São Joaquim não cobria as despesas de funcionamento . Em acréscimo, a estação de São Joaquim era inadequada como um ponto de distribuição pela sua falta de espaço, sua localização não era central e as ruas circunvizinhas eram más para carroças. Por essas razões a companhia solicitou um aumento de taxa para $3 \$ 000$ réis por cada rez abatida e pediu que o ponto de distribuição fosse mudado para um novo local perto do mercado velho. Dando força a este pedido havia um tênue veu de ameaça. Com as mudanças propostas a companhia podia melhorar seus serviços; sem eles, teria que suspender seu tráfego. Mesmo que uma nova companhia fosse organizada para dar prosseguimento ao serviço, teria que ser estabelecida tão rapidamente que o resultado seria maiores gastos e irregularidades (74).

A ameaça da companhia foi suficientemente assustadora para advertir oitenta,

$$
\text { "residentes, industriais, negociantes e proprietários" }
$$

de Santo Amaro a propor uma solução para evitar a suspensão do tráfego. Em negociações particulares com a companhia chegaram a um acordo sobre uma nova tabela, e agora eles pressionaram a sua adoção à Secretaria da Agricultura, pois um encerramento seria uma ruína para a companhia e para os interesses de seu município (75). Em 7 de maio, estes receios foram confirmados, pois a companhia cumpriu a sua ameaça e encerrou a linha. Os jornais da cidade tornaram-se um forum para debates com ataques e contra-ataques. $O$ Correio Paulistano elogiou a intransigência do Estado. Como pode o governo conceder um aumento de taxas para uma companhia que

\footnotetext{
"não quer fazer sacrifícios para melhorar o serviço e exige o dobro do preço por um trabalho mau feito?" (76).
}

A decisão para suspender o tráfego não foi nada mais do que uma medida de represália contra a energia do governo e a justa defesa aos interesses do povo. Alem disso, se a companhia estava impossibilitada de melhorar o seu serviço com um aumento nas taxas, era óbvio que

(74). - Ibidem.

(75). - Abaixo assinado ao Secretário da Agricultura, 6 de maio de 1893. Secrtaria da Agricultura, Ofícios Diversos, 1893, No 4.158, caixa 38, ASP. (76). - Correio Paulistano, 7-5-1893. 


\begin{abstract}
"uma empresa arruinada, incapaz de desempenhar a função que se presta hoje ou amanhã terá que baquear" (77).
\end{abstract}

Uma vez mais a companhia ergueu-se para sua própria defesa, e taxou os ataques do Correio Paulistano como inexatos e insultantes. $\mathrm{O}$ deficit financeiro, não por vingança, causou a suspensão da linha. O aumento da taxa deveria ser usado para cobrir este deficit; por esta razão o dinheiro não poderia ser usado para comprar material rodante . Com referência a imparcialidade da posição do governo, os resultados falam por si mesmos: Santo Amaro seria privada do serviço da companhia, na verdade muito injusto, uma vez que os habitantes de Santo Amaro aceitaram o aumento das taxas como sendo razoavel (78).

Enquanto a retórica corria, os bondes de Santo Amaro permaneram estacionados. Com sua grande dependência dos carros da companhia para o transporte da carne para a cidade, a Municipalidade de São Paulo fez um ajuste particular (79). O Estado, entretanto, sentiu menos pressão e continuou a briga. Em 12 de maio de 1893, 116 moradores do município e vila de Santo Amaro pediram que o tráfego se restabelecesse. Os 10.000 habitantes do município disseram que não podiam continuar a serem privados de suas relações civis, comerciais e sociais com a Capital, porque era de São Paulo que surgiam as bases do seu progresso.

"Com a criação da linha de bondes a vapor, o município de Santo Amaro teve poderoso impulso, não só valorizando seus terrenos, como foram fundados diversos estabelecimentos industriais. Ora, é certo que, interrompido o tráfego, tão elevados interesses industriais e comerciais sofreram golpe tremendo que aniquilará fatalmente os capitais comprometidos sob a fé da lei que criou a companhia de bondes".

(77). - Ibidem.

(78). - Diário Popular, 8-5-1893.

Isso deveria ter sido uma referência ao concordo com os oitenta residentes, negociantes e proprietários de Santo Amaro, veja nota 74 .

(79). - Relatório apresentado à Câmara Municipal de São Paulo pelo Intendente Municipal Cesário Ramalho da Silva, 1893. Typ. de Espindola, Siqueira \& Comp., São Paulo, 1893, p. 14. Observou o Intendente: "A fim de afastar os motivos que determinavam as dificuldades de transporte, pois que o tráfego da Estrada de Ferro São Paulo à Santo Amaro achava-se suspenso, reaiizei um convênio com a administração da mesma no intuito de ser mantido o horário com a devida regularidade, ficando estabelecida uma pequena alteração no preço do frete...". Ibidem. 
Os recorrentes disseram que preferiam, por esta razão, o sacrifício de pagar taxas mais altas a uma interminavel interrupção do tráfego (80). O Governo do Estado, contudo, não estava mais disposto a fazer esse sacrifício. José Luiz Coelho, chefe da segunda seção da Superintendência de Obras Públicas, observando que os 116 que apareceram querendo a reabertura da linha a qualquer preço, apontaram que eles não representavam todos os moradores de Santo Amaro que usavam a linha. A companhia, ele continuou, tem privilégios contratuais, a exclusão de concorrência, e é obrigada por esta razão a servir de uma maneira que não abuse desse monopólio. Em grande escala os problemas financeiros da companhia resultaram de sua incapacidade de direção. Sua má escolha de tipos de trilhos e a insuficiência de vagões levaram muitos industriais a abandonar a linha (81). Posteriormente, ainda não sem condições, o governo autorizou o aumento da taxa variando de $48 \%$ a $150 \%$ acima da velha tabela (82). Então, em 7 de junho de 1893 a companhia reabriu o tráfego para Santo Amaro. Mas, não aproveitando as lições das experiências anteriores, a companhia retornou à sua antiga prática, e começou cobrando taxas que excediam os limites combinados, por $100 \%$ (83)! Com todo o furor as negociações pouco resolveram e nada mudaram. A condição financeira da companhia continuou a decair, e as queixas públicas continuaram grandes. Por 1899 a companhia entrou em liquidação forçada, e críticas à linha eram muito semelhantes àquelas de 6 anos atrás, horário incerto, falta de manutenção, vagões inadequados (84). No ano seguinte em hasta pública a companhia foi arrematada pela Light por um preço total de 152 contos (85), mais ou menos a metade da capitalização original (86) .

A história da Companhia Santo Amaro não é única; pelo contrário, ela exemplifica todas as tentativas anteriores para estabelecer um

(80) . - Abaixo-assinado a Jorge Tibiriçá, 12 de maio de 1893. Secretaria da Agricultura, Ofícios Diversos, 1893 , No 4.159 , caixa 39, ASP.

(81). - José Luiz Coelho ao Diretor da Superintendência das Obras Públicas, 7-6-1893. Ibidem.

(82). - Ibidem. O menor aumento era na tarifa de passageiros, o maior, no transporte da carne fresca. A não ser a tarifa para carvão que subiu $54 \%$, as tarifas de carga aumentaram de $100 \%$ a $127 \%$.

(83). - José Pereira Rebouças ao Secretário d'Agricultura, Commércio e Obras Públicas, 13 de junho de 1893. Secretaria da Agricultura, Ofícios Diversos, 1893 , No 4.159 , caixa 39 , ASP.

(84). - José Luiz Coelho ao Secretário de Agricultura, 27 de julho de 1899. Secretaria da Agricultura, Ofícios Diversos, 1899, No 4.323, caixa 204, ASP.

(85) . - Light, Memorial, op. cit., p. 4.

(86). - A capitalização da Companhia Santo Amaro, era 300:000\$000 réis. Relatốrio Eugênio da Silva, op. cit. 
sistema de transporte urbano em São Paulo. Problemas criados por conflitos entre as autoridades governamentais eram comuns às experiências de todas essas companhias. De uma maneira parecida, promessa inicial de lucros e serviços, resultando posteriormente em decepção para ambos, as companhias e o público, era uma regra típica. Por ironia, a zona de privilégio, vista pelas companhias como sendo a chave para prosperidade, provou ser a maior causa de desilusão pública e privada. Permitir um monopólio eficaz era lógico no tempo da concessão original para a Companhia Carris de Ferro. O serviço prometido era novo, e era prefeitamente imaginavel que os empresários merecessem uma compensação garantida e o direito de expandir suas companhias. Mas este monopólio tornou-se um embaraço, quando a companhia não pode fornecer um seviço adequado às necessidades crescentes de transporte resultante do crescimento da cidade em população e extensão (87). Até então, por volta de 1884, a Câmara Municipal de São Paulo estava concedendo novas concessões e o governo provincial começou um processo de reinterpretação dos privilégios da Companhia Carris de Ferro. Em 1886, conquanto ainda negasse autorização para o funcionamento de linhas que estivessem em conflito com a zona de privilégio da companhia, o governo demonstrou que afinal o monopólio não éra cego. A companhia tinha o direito de preferência por quaisquer linhas novas, mas se esta não pudesse prosseguir, as concessões de serviço podiam ser concedidas a outros (88). Uma vez este nicho aberto, a zona tornou-se mais um onus do que um benefício, porque outros empresários pediram concessões sabendo que as companhias existentes seriam forçadas a extender suas linhas ou perder o privilégio. Ações forçosas como estas apresentaram às companhias existentes um sério dilema, o que frequentemente resultava em sacrifícios financeiros. A. Lopes de Leão, engenheiro da Intendência, comentando sobre a asserção da Viação Paulista, que falta de dinheiro os impediu de fazer melhorias, observou que a companhia tinha gasto seu dinheiro colocando várias linhas, que não são usadas, de maneira a impedir outras companhias de obterem o privilégio: $O$ resultado, logicamente, foi que o público perdeu o serviço que eles poderiam estar tendo de outras empresas (89).

(87). - Prudente, 20 de janeiro de 1890, op. cit.

Luiz C. do Amaral Gama ao Presidente da Câmara Municipal de São Paulo, 29 de dezembro de 1889. Papeis Avulsos, 1890, vol. 1, AM.

(88) - - Relatório apresentado à Assembléia Legislativa Provincial, 1886, op. cit. "Leis não sancionadas", p. 3. De fato, a decisão de Prudente a favor da Companhia Ferro Carril fundou-se, em parte, nesta interpretação.

(89). - A. Lopes de Leão a Carlos Garcia Ferreira, 13 de agosto de 1892. Secretaria d'Agricultura, Oficios Diversos, 1892, No 4.144, caixa 4, ASP. 
As reivindicações da dificuldade financeira não foram completamente à toa. Na década de 1890 o câmbio baixou rigidamente e permaneceu depreciado (90). Como muitos carros e locomotivas vieram da Europa, isto criou sérias dificuldades para as companhias de transporte. Na verdade, a Viação Paulista informou a seus acionistas que em virtude da mudança das taxas ela foi forçada a pagar três vezes mais do que o previsto para materiais encomendados no exterior (91). Em acréscimo, a década de 1890 em São Paulo testemunhou um período de inflação, um notavel aumento de custo de vida (92). Isto tambem provocou a ruina financeira entre as várias companhias de transportes, à medida que eram forçadas a pagar mais para o seu pessoal e pelos materiais utilizados para manter as operações. Até então, em 1893 o concessionário para a linha da Ponte Grande à Cantareira solicitou uma modificação nos preços acertados na concessão original, pois os custos de trabalhos, materiais e mão-de-obra, eram o dobro do que eram quando assinou o contrato em 1890 (93). Neste mesmo tempo, João Bueno, Intendente da Justiça e Polícia Municipal, explicou que havia trabalhado para aumentar o atendimento das companhias às reclamações do público, mas sem força-los a gastar mais do que eram capazes,

"tendo em vista a crise do alto preço que atingiu o salário e os gêneros de consumo nesta cidade" (94).

Obviamente, companhias surpreendidas sonegando foram impossibilitadas de melhorar e refinar seus servicos e ajustar-se com as novas demandas. Até então, as primitivas companhias de viação afastaram-se, pois mesmo combinando, só multiplicou fraquesa, e quando uma bem capitalizada concorrência surgiu, representada pela Light, eles puderam oferecer uma pequena resistência.

Contudo, é errôneo presumir que essas companhias falharam completamente. Em verdade, a sua real medida de sucesso em fornecer

(90). - Furtado (Celso), The Economic Growth of Brazil, A Survey flom Colonial to Modern Times. Tradução de Ricardo W. de Aguiar e Eric Charles Drysdale. University of California Press, Berkeley and Los Angeles, 1965 , p. 180 .

(91) . - Presidente da Companhia Viação Paulista ao Presidente do Estado, 20 de abril de 1893. Secretaria da Agricultura, Ofícios Diversos, 1893, № 4.155, caixa 35, ASP.

(92). - Reclamações e comentários sobre o alto do custo da vida eram comuns durante a década. Veja, por exemplo: Anais da Câmara dos Deputados, 1891, p. 791; Relatório do Intendente Municipal, 1893, p. 117; Atas da Câmara Municipal de São Paulo, 1896, p. 587, e 1899, p. 454.

(93). - Companhia Construtora ao Presidente e Membros da Câmara Municipal, 25 de fevereiro de 1893. Papéis Avulsos, 1893, vol. 6, AM.

(94) . - João Bueno ao Presidente e Vereadores da Câmara Municipal, 25 de fevereiro de 1893, Papéis Avulsos, 1893, vol. 3, AM. 
um serviço valioso foi a posterior causa de sua ruina. Tendo permanecido o transporte público uma novidade ou luxo, é duvidoso que as reclamações do público tenham sido tão evidentes. No seu início a Companhia Santo Amaro não poderia competir nem tão pouco com os carros de boi, todavia, oito anos mais tarde a suspensão da linha foi vista como uma calamidade. Como alguns bairros lucraram com o serviço de bondes, habitantes de outros bairros, perfeitamente natural, requereram tambem que fossem servidos.

Ainda que o crescimento de São Paulo fosse o fator causativo fundamental de um aumento do interesse público em transportes urbanos, foi o sucesso das companhias mostrando as vantagens decorrentes do tal sistema que o dirigiu. Como Silva Bruno certamente observou,

"de qualquer forma, porém, (os bondes) representaram um melhorameito consideravel na época, para a existência da cidade (95).

Parafraseando este autor, poderíamos acrescentar que

"de qualquer forma, a frequente incidência e violência das reclamações, podem ser vistos como um índice precioso da imediata e vital importância da viação urbana em São Paulo".

\section{RELATÓRIOS:}

Exposição, com que o exm. snr. Visconde do Parnahyba passou a administração da provincia de São Paulo ao exm. snr. Dr. Francisco de Paula Rodrigues Alves, presidente desta provincia no dia 19 de novembro de 1887. Typ. de Jorge Seckler \& Comp., São Paulo, 1888.

Relatório annual da seç̧ão de obras da Intendencia Municipal de São Paulo, 1894, apresentado ao cidadão Cesario Ramalho da Silva, M. D. Intendente Municipal, por J.F. Ortiz, Engenheiro-Chefe Interino. Typ. Espindola, Siqueira \& Comp., São Paulo, 1895.

Relatório apresentado à assembléia legislativa provincial de São Paulo pelo presidente da provincia João Alfredo Corrêa de Oliveira no dia 15 de fevereiro de 1886. Typ. de Jorge Seckler \& C., São Paulo, 1886.

(95). - Silva Bruno (Ernani), História e tradiçóes da cidade de São Paulo, 3 vol., Comissão do IV Centenário de São Paulo, 1954, vol. 3, p. 1075. 
Relatório apresentado à assembléia legislativa provincial de São Paulo pelo presidente da provincia Barão do Parnahyba no dia 17 de janeiro de 1887. Typ. de Jorge Seckler \& Comp., São Paulo, 1887.

Kelatório apresentado à Câmara Municipal de São Paulo pelo intendénte municipal Cesario Ramalho da Silva, 1893. Typ. de Espindola, Siqueira \& Comp., São Paulo, 1894.

Relatório apresentado ao Dr. Presidente do Estado de São Paulo pelo Dr. Jorge Tibiriçá, Secretario dos negocios da agricultura, commercio $e$ obras publicas, em 4 de abril de 1893. Typ. G. Leuzinger \& Filhos, Rio de Janeiro, 1893.

Relatório apresentado pela superintendencia de obras publicas do Estado de São Paulo em 31 de março de 1892, ao cidadão Dr. Alfredo Maia, digno secretario dos negocios d'agricultura, commercio e obras publicas deste estado. Typ. Vanorden \& Cia., São Paulo, 1892.

Relatório de Eugenio da Silva, engenheiro fiscal da Companhia Carris de Ferro São Paulo à Santo Amaro, 1885. Relatórios Diversos, 1864-1885, Arquivo do Estado de São Paulo.

Kelatório da directoria da Companhia Viação Paulista apresentado à assembléia geral de accionistas em 10 de março de 1893. Typ. Hennies \& Winiger, São Paulo, 1893.

\section{LIVROS E REVISTAS:}

Bandecchi (Pedro Brasil), "São Paulo - de cidade provinciana à metrópole", em Curso de História de São Paulo, Prefeitura do Município de São Paulo, Secretaria de Educação e Cultura, Divisão do Arquivo Histórico, São Paulo, 1969.

Davis (Kingsley) e Golden (Hilda Hertz), "Urbanization and the Development of Pre-Industrial Areas", in Hatt (Paul K.) and Reiss (Albert J. Jr.), Cities and Society. The Revised Reader in Urban Sociology, The. Free Press, Glencoe, Ill., 1957.

Geiger (Pedro Pinchas), Evolução da rede urbana brasileira. Centro Brasileiro de Pesquisas Educacionais, Instituto Nacional de Estudos Pedagógicos, Ministério da Educação e Cultura - Brasil, Rio de Janeiro, 1963.

Hatt (Paul K.) e Reiss (Albert J.), eds., Cities and Society. The Revised Reader in Urban Sociology, The Free Press, Glencoe, Ill., 1957.

IBGE, Conselho Nacional de Estatística, Synopse estatística do Município de São Paulo, Serviço gráfico do IBGE, Rio de Janeiro, 1950.

Johnson (James H.), Urban Geography, An Introductory Analysis. The Commonwealth and International Library. Pergamon Press, Oxford, 1967. 
Mayer (Harold M.), "A Survey of Urban Geography", in Hauser (Philip) e Schnore (Leo), The Study of Urbanization. John Wiley \& Sons, New York, 1965.

Memorial sobre o serviço de transporte collectivo apresentado à Câmara $\mathrm{Mu}$ nicipal de São Paulo pela The São Paulo Tramway, Light \& Power Company Ltd., 1927.

Nogueira de Matos (Odilon), "São Paulo no século XIX", em Azevedo (Aroldo de) e outros, $A$ cidade de São Paulo. Estudos de geografia urbana por um grupo de geógrafos sob a direção de Aroldo de Azevedo. Associação dos Geógrafos Brasileiros, Seç̧ão Regional de São Paulo, Companhia Editora Nacional, São Paulo, 1958. Vol.

Prado Júnior (Caio), "Nova contribuição para o estudo geográfico da cidade de São Paulo", Estudos Brasileiros, Ano III, v. 7, 1941.

"O factor geográfico na formação e no desenvolvimento da cidade de São Paulo", em Evolução política do Brasil e outros estudos. Editora Brasilierise Ltda., São Paulo, 1953.

Silva Bruno (Ernani), História e tradições da cidade de São Paulo. 3 vol. Comissão do IV Centenário de São Paulo, 1954. Vol. 3.

Singer (Paulo), Desenvolvimento econômico e evolução urbana, análisé da evolução econômica de São Paulo, Blumenau, Porto Alegre, Belo Horizonte e Recife, Editora Nacional, São Paulo, 1968.

The São Paulo Tramway Light and Power Co., Limited. Cinquenta anos com São Paulo, 1900-1950.

\section{BJBLIOGRAFLA.}

\section{LOCUMENOS INEDITOS:}

Gêneros entrados no mercado, 1885, Livro 2, No 1305: Arquivo Municipal Washington Luis.

Intendências Municipais, 1889-1891, No 5540, caixa 1 - No 5551, caixa 12. Arquivo do Estado de São Paulo.

Obras Públicas, 1885-1890, № 5192, caixa 55 - No 5211, caixa 74. Arquivo do Estado de São Paulo.

Obras Particulares, Papéis Avulsos, 1885-1893. Arquivo Municipal Washington Luis.

Relatórios Diversos, 1864-1913, No 5652, caixa $1-\mathrm{N}$ \% 5654, caixa 3. Arquivo do Estado de São Paulo.

Secretaria da Agricultura, Ofícios Diversos, 1881-1901, No 4121, caixa No 4432, caixa 313. Arquivo do Estado de São Paulo.

\section{COLEÇÕES DE DOCUMENTOS:}

Anais da Câmara dos Deputados, 1891. 
Atas da Câmara Municipal de São Paulo, 1882-1900. Departamento de Cultura da Prefeitura de São Paulo.

Leis e Decretos do Estado de São Paulo, 1885-1902.

Leis e Decretos da Prefeitura Municipal de São Paulo, 1892-1902.

JORNAIS:

Correio Paulistano, 1893.

Diário Oficial do Estado de São Paulo, 1891 e 1893 .

Diário Popular, 1885-1901.

Estado de São Paulo, 13-3-1908 - 25-1-1909. 